\title{
Erratum to: Media in the Middle East
}

\author{
Nele Lenze, Charlotte Schriwer and Zubaidah Abdul Jalil
}

\section{Erratum to:}

N. Lenze et al. (eds.), Media in the Middle East, https://doi.org/10.1007/978-3-319-65771-4

The original version of the book was inadvertently published without incorporating the following corrections:

In Chapter 10, chapter author's last name was incorrectly captured as "Panovic" ("c" instead of accent character "ć"), which has been now corrected as "Panović".

In Frontmatter, the text "BA in Oriental Philology from the University of Belgrade" has been newly included in "Notes on Contributors" of the author "Ivan Panović" as follows:

"Ivan Panović is an Assistant Professor of Linguistics and Multilingual Studies at Nanyang Technological University, Singapore. He has a BA in Oriental Philology from the University of Belgrade, an MA in Sociology \& Anthropology from the American University in Cairo, and a DPhil in Oriental Studies from the University of Oxford. He is the co-author (with Deborah Cameron) of Working with Written Discourse (London: SAGE Publications, 2014).”

The updated online version of this book can be found at https://doi.org/10.1007/978-3-319-65771-4_10 and https://doi.org/10.1007/978-3-319-65771-4

(C) The Author(s) 2018 E1

N. Lenze et al. (eds.), Media in the Middle East, https://doi.org/10.1007/978-3-319-65771-4_11 